\title{
DOES BIRTH WEIGHT INFLUENCE THE AGE OF MENARCHE? A CROSS SECTIONAL STUDY IN RURAL KERALA
}

\author{
Resmy. C. Raveendran ${ }^{1}$, Anju Mariam Jacob², Jisha Ismail ${ }^{3}$
}

${ }^{1}$ Associate Professor, Department of Obstetrics and Gynaecology, Government Medical College, Thrissur.

${ }^{2}$ Associate Professor, Department of Anaesthesiology, Government Medical College, Thrissur.

${ }^{3}$ Assistant Professor, Department of Obstetrics and Gynaecology, Government Medical College, Thrissur.

\section{ABSTRACT}

\section{BACKGROUND}

Age of menarche is showing a declining trend in all parts of the world. The reasons for this decline is proposed to be related to improvement in nutritional status, environmental factors, heredity, and body mass index. Weight at birth of the child has also been considered to influence the onset of menarche.

The aim of the study is to identify whether birth weight influenced the age of menarche in girls.

\section{MATERIALS AND METHODS}

Settings and Design- This study was conducted in a school in a rural area in Kerala with limited access to urbanisation. It was a cross sectional study among 232 adolescent girls between 12 and 17 years studying in class 8 to 11 in the school. A semistructured questionnaire proforma was used to collect data. This was done after awareness classes were given to the girls and consent from the girls and their parents obtained. Data collected was analysed using SPSS 16 software. Linear correlation between age of menarche and birth weight as well as between age of menarche and BMI were determined.

\section{RESULTS}

Of the 232 girls who consented to share the information, 193 girls (83.2\%) had attained menarche of which majority of them (135 girls) attained menarche between 12-14 years. Mean age of menarche was 12.67 yrs. \pm 0.959 (SD) and mean birth weight of the girls was $2.77 \mathrm{~kg} \pm 0.53(\mathrm{SD})$. No significant correlation was found between birth weight and age of menarche and present BMI and age of menarche in the study.

\section{CONCLUSION}

Birth weight did not show a significant correlation with age of onset of menarche in this study. Other confounding factors such as heredity and environment may have played an influence.

\section{KEYWORDS}

Birth Weight, Age of Menarche, Rural Kerala.

HOW TO CITE THIS ARTICLE: Raveendran RC, Jacob AM, Ismail J. Does birth weight influence the age of menarche? A cross sectional study in rural Kerala. J. Evolution Med. Dent. Sci. 2017;6(1):10-13, DOI: 10.14260/Jemds/2017/4

\section{BACKGROUND}

Menarche denotes the beginning of the fertile epoch in a woman's life. With time, it is seen that age of menarche is declining. In the mid $19^{\text {th }}$ century, the average age of menarche was 17 years, but by 2002 it had dropped to 12.5 years.1,2 This may be due to the changes in social circumstances, better nutrition, changes in body fat and lifestyle changes which may be due to urbanisation of the population. ${ }^{3}$

Several factors including genetics, body stature, family size, body mass index, socioeconomic status, and the level of education have been found to significantly influence age of menarche. ${ }^{4}$

Financial or Other, Competing Interest: None.

Submission 25-11-2016, Peer Review 19-12-2016,

Acceptance 25-12-2016, Published 02-01-2017.

Corresponding Author:

Dr. Resmy C. Raveendran,

Associate Professor,

Department of Obstetrics and Gynaecology,

Government Medical College, Thrissur.

E-mail: drresmy@gmail.com

DOI: $10.14260 /$ jemds $/ 2017 / 4$
Birth weight has been speculated to influence age of onset of menarche. Some studies showed that a lower birth weight was associated with earlier age of menarche.5,6 Opposing influence of body fat has been seen in some of these studies. Even though low birth weight was linked to earlier onset of menarche, higher body fat distribution and height in childhood was also associated with an earlier menarche. ${ }^{6}$ Our study was conducted in rural Kerala to find the factors influencing the age of menarche. Kerala has always shown leading trends in health indices among the Indian states. It has also been looked upon by WHO as an example of good health in the world and is known as the "Kerala model."7 Most parts of Kerala have undergone urbanisation on a large scale which may influence the factors affecting the onset of menarche. ${ }^{8}$ But the rural-urban divide is still wide in some rural areas in Kerala. Hence, this study setting was planned in such a rural area, to determine whether birth weight and body mass index influenced age of menarche as it may not have the influences of urbanisation on its population.

\section{MATERIALS AND METHODS}

This was an analytical study conducted in a school in rural Kerala in the year 2013. Institutional ethical committee clearance was obtained before the study was started. 
A rural government school in Thrissur district, Kerala, about $50 \mathrm{~km}$ from town was identified, which had minimum access to urban utilities in the district. Girls studying in the school from $8^{\text {th }}$ grade to 11 th grade were given reproductive awareness class. Around 300 girls between 11 to 17 years participated in the classes. Awareness regarding menarche and the changes during menarche, normal menstrual pattern, and common menstrual complaints were highlighted. Consent for participation in the study was taken from both the students and their parents. 232 girls consented to participate in the study.

A self-evaluation proforma was drawn out which included questions on birth weight, age of menarche, present height and weight of the student and menstrual problems, if any. The proforma had to be filled by the student and the parents jointly, which was done at their respective residences. Birth weight was, reconfirmed by checking with the birth records available. Age of menarche, weight at menarche (If they were able to recall), other menstrual problems experienced by the girls were also noted. The participants were assured of strict confidentiality regarding their identity.

The data was entered in excel worksheet and analysed using SPSS 16 software. Data from 232 girls who consented to give the necessary information were analysed. Relationship between age of menarche (Among the girls who had attained menarche) and birth weight were determined using linear correlation. The data of girls with birth weight not known were not included in the correlation. Pearson coefficient was determined to assess the strength of the relation between the 2 variables.

\section{RESULTS}

300 girls were given reproductive awareness class out of which 232 girls and their parents consented to divulge the information sought in the proforma. All girls were between 12 yrs. to 17 yrs.

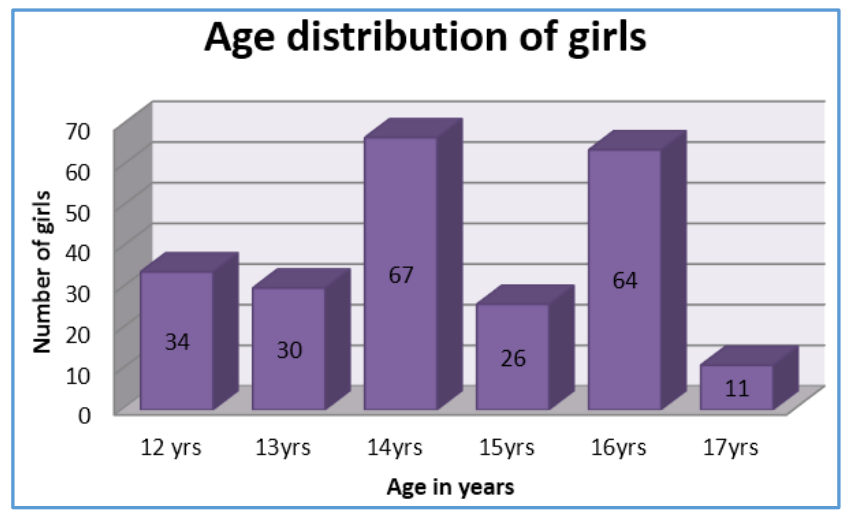

Figure 1

Out of the 232 girls, 34 girls (14.7\%) were 12 yrs. of age, 30 girls (12.9\%) were 13 yrs. of age, 67 girls (28.9\%) were 14 yrs. of age, 26 girls (11.2\%) were 15 yrs. of age, 64 girls $(27.6 \%)$ were 16 yrs. of age and 11 girls (4.7\%) were 17 yrs. of age.

\section{Socioeconomic distribution}

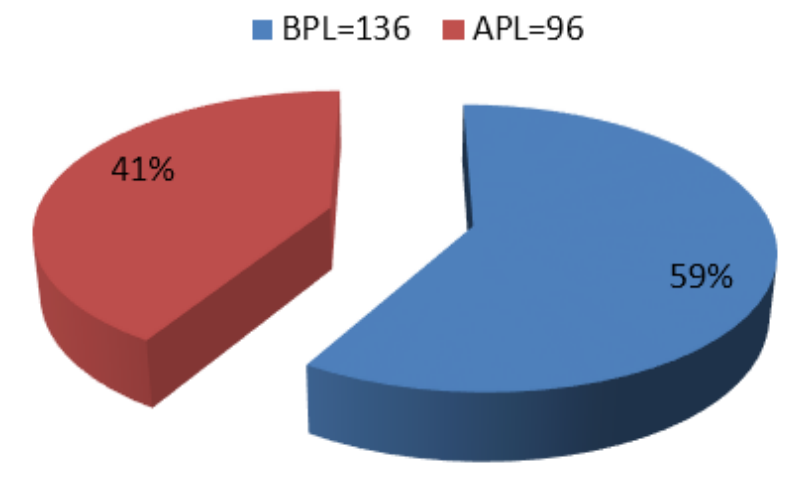

Figure 2

BPL-Below poverty line APL-Above poverty line.

Of the 232 girls 136(59\%) girls belonged to below poverty line (BPL) while 96(41\%) girls belonged above poverty line (APL).

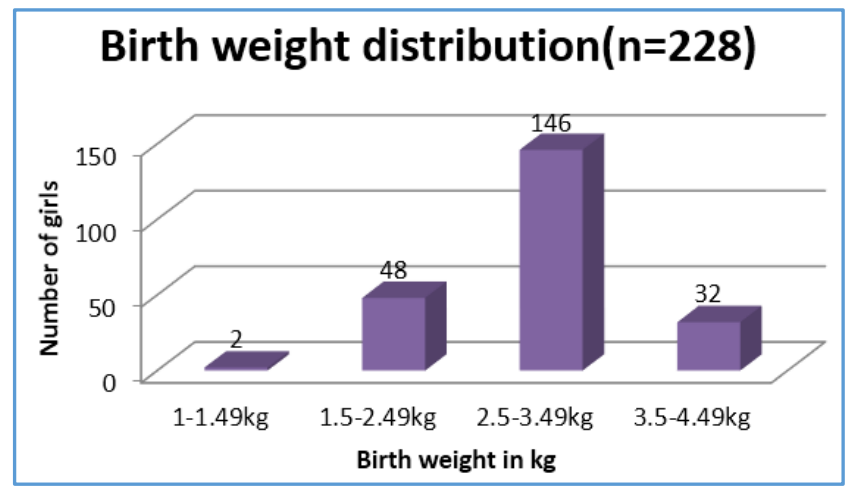

Figure 3

Birth weight of 4 girls was not known as they did not have any proper documents with them.

2 girls $(0.87 \%)$ had birth weight less than $1.5 \mathrm{~kg}, 48$ (21.05\%) girls had birth weight between $1.5 \mathrm{~kg}$ to $2.49 \mathrm{~kg}$, $146(64.04 \%)$ girls had birth weight between $2.5 \mathrm{~kg}$ to 3.49 $\mathrm{kg}, 32$ girls (14.04\%) had birth weight more than $3.5 \mathrm{~kg}$. Mean birth weight of the study group was found to be $2.77 \mathrm{~kg}$ \pm 0.53 (SD).

\section{Age of Menarche}

Out of the 232 girls, 39 girls (16.8\%) had not attained menarche. Out of this, 21 girls (53.8\%) were less than 13 years and 10 girls (25.64\%) were between 13 to 13.9 yrs. 3 girls (7.7\%) had not attained menarche even after 15 years, of which one girl had not attained menarche even after 16 years, which needs to be evaluated as primary amenorrhoea.

\begin{tabular}{|c|c|c|c|c|c|}
\hline $\begin{array}{c}\text { Age of Girls } \\
\text { (In years) }\end{array}$ & $12-12.9$ & $13-13.9$ & $14-14.9$ & $15-15.9$ & $>16$ \\
\hline No. of Girls & 21 & 10 & 5 & 2 & 1 \\
\hline Percentage & $53.8 \%$ & $25.64 \%$ & $12.8 \%$ & $5.12 \%$ & $2.56 \%$ \\
\hline \multicolumn{6}{|c|}{ Table 1: Not Attained Menarche (n=39) }
\end{tabular}


193 girls had attained menarche in the study group of which 68 girls (35.2\%) were between 12 to 12.9 yrs and 67 girls $(34.7 \%)$ were between 13 to 13.9 yrs. That is, 135 girls (69.9\%) who had attained menarche were between 12 to 14 yrs, which is similar to the Indian scenario. 40 girls (20.7\%) attained menarche at a relatively later age of more than 14 years. Mean age of menarche was 12.67 yrs. \pm 0.959 (SD).

\begin{tabular}{|c|c|c|c|c|c|c|c|}
\hline $\begin{array}{c}\text { Age } \\
\text { of Girls } \\
\text { (In years) }\end{array}$ & $<10$ & $\begin{array}{c}10- \\
10.9\end{array}$ & $\begin{array}{c}11- \\
11.9\end{array}$ & $\begin{array}{c}12- \\
12.9\end{array}$ & $\begin{array}{c}13- \\
13.9\end{array}$ & $\begin{array}{c}14- \\
14.9\end{array}$ & $>15$ \\
\hline $\begin{array}{c}\text { Number of } \\
\text { Girls }\end{array}$ & 0 & 3 & 15 & 68 & 67 & 38 & 2 \\
\hline Percentage & $0 \%$ & $1.6 \%$ & $7.77 \%$ & $35.2 \%$ & $34.7 \%$ & $19.7 \%$ & $1.03 \%$ \\
\hline \multicolumn{7}{|c|}{ Table 2. Age of Attaining Menarche (n=193) } \\
\hline
\end{tabular}

\section{Distribution of Body Mass Index}

230 girls fell between the $5^{\text {th }}$ percentile and $85^{\text {th }}$ percentile of body mass index within their age group which quantified as healthy weight. No child was overweight or obese. 2 children had BMI below the $5^{\text {th }}$ percentile with respect to age which could be quantified as underweight. The mean BMI was 17.3.

\section{Relation between Age of Menarche and Birth Weight}

No significant positive correlation was found between birth weight and age of menarche ( $p=0.593$, Correlation coefficient 0. 039) from the data of the 189 girls who had attained menarche and birth weight was available (Excluding the 4 girls with no birth weight available from 193 girls who had attained menarche).

Relation between Age of Menarche and Body Mass Index No significant correlation was found between age of menarche and current BMI. ( $\mathrm{p}=0.518$, correlation coefficient 0. 047).

\section{DISCUSSION}

Age at menarche in a girl carries psychological and social significance with major physical and emotional changes happening during these years. Early age of menarche is associated with an increased incidence of breast cancer, endometrial cancer, menstrual problems and adult obesity.9,10,11 There are many factors attributed to age of attaining menarche. These include socioeconomic background, body fat distribution, heredity, weight at birth and weight gain during the initial childhood days.

Menarche is usually seen to be attained between 12 and 13 years. ${ }^{12}$ The age at which menarche is attained is reducing with time. ${ }^{13}$ In India, the age at menarche is found to be around 13 to 14 years and is declining. ${ }^{14}$ The mean age of menarche in various studies ranges from 12.65 to 13.67 yrs. ${ }^{14,15}$

In our study, majority of the girls attained menarche between 12 to 14 years. The mean age at menarche of the girls was seen to be $12.67 \pm 0.959$ (SD) years which is comparable to other studies conducted in Kerala by M. K. C. Nair et al. ${ }^{15}$ None of the girls showed precocious onset of menarche. This may be due to the setting of the study where all urban influences were possibly eliminated, one of the main causes of precocious puberty postulated being obesity which is more commonly seen in urban areas. ${ }^{16,17}$
Prevalence of precocious puberty in developed countries has been found to be about 20-23 per 10000.18

The mean birth weight among the girls who participated in the study was $2.77 \mathrm{~kg} \pm 0.53$ (SD) which is comparable to the Indian birth weight. ${ }^{19}$ Birth weight has been speculated to influence age of menarche. Some studies showed that a lower birth weight was associated with earlier age of menarche. 5 There has been conflicting report of lighter birth weight being associated with an earlier onset of menarche while higher body fat distribution and height in childhood was associated with an earlier menarche. ${ }^{6} \mathrm{~A}$ study conducted by Terry MB et al in an ethnically and racially diverse cohort in US found that girls who weighed more with more body fat distribution at the age of 7 years attained earlier menarche. ${ }^{20}$ This study also showed that girls who weighed lighter at birth had an earlier age of menarche, but no statistical significant correlation was observed. Our study also showed no significant relation between birth weight and age of menarche.

In our study, no correlation between age of menarche and present body mass index of the girls was found. Studies conducted in different parts of the world have shown conflicting results. A study conducted in Kuwait among 1200 girls found that there was a delay in onset of menarche in obese and overweight girls. ${ }^{21}$ This result was in contrast to the study conducted in US. ${ }^{20}$ In our study, most of the girls did not know their weight or height at the time of menarche and therefore the BMI at the time of menarche could not be calculated. Thus, we could not find out whether there was a correlation between age at menarche and BMI at menarche, this may be considered a limitation in our study.

\section{CONCLUSION}

The birth weight and present body mass index did not show a correlation with the age of onset of menarche. Other confounding factors like heredity, environmental factors might have played a role in influencing the age of menarche. Different studies have given conflicting evidence with respect to relation between birth weight and age of onset of menarche. Hence, further studies may be needed to identify other confounding factors which may influence the onset of menarche. Since earlier age of menarche poses reproductive and health risks, identification of the modifiable factors affecting the age of menarche will help in the improvement of the long term health of the girl child.

\section{Acknowledgements}

We thank the school authorities for permitting us to conduct this study in their school. We also thank all the children and their parents who willingly took part in the study.

\section{REFERENCES}

[1] Demerath EW, Towne B, Chumlea WC, et al. Recent decline in age at menarche: The Fel's longitudinal study. American Journal of Human Biology 2004;16(4):453-7.

[2] van Lenthe FJ, Kemper CG, van Mechelen W. Rapid maturation in adolescence results in greater obesity in adulthood: the Amsterdam growth and health study. The American journal of clinical nutrition 1996;64(1):18-24.

[3] Winter S, Ousidhoum A, McElreavey $\mathrm{K}$, et al. Constitutional delay of puberty: presentation and inheritance pattern in 48 familial cases. BMC pediatrics 2016;16:37. 
[4] Mpora BO, Piloya T, Awor S, et al. Age at menarche in relation to nutritional status and critical life events among rural and urban secondary school girls in postconflict northern Uganda. BMC women's health 2014;14:66.

[5] Romundstad PR, Vatten LJ, Nilsen TI, et al. Birth size in relation to age at menarche and adolescent body size: implications for breast cancer risk. International journal of cancer 2003;105(3):400-3.

[6] Tam CS, de Zegher F, Garnett SP, et al. Opposing influences of prenatal and postnatal growth on the timing of menarche. The Journal of Clinical Endocrinology \& Metabolism 2006;91(11):4369-73.

[7] Parayil G. The Kerala model of development: development and sustainability in the third world. Third World Quarterly 1996;17(5):941-58.

[8] Bhagat RB. Emerging pattern of urbanisation in India. Economic and Political Weekly 2011;46(34):10-2.

[9] Kelsey JL, Gammon MD, John EM. Reproductive factors and breast cancer. Epidemiologic reviews 1993;15(1):36-47.

[10] La Vecchia C, Franceschi S, Decarli A, et al. Risk factors for endometrial cancer at different ages. Journal of the National Cancer Institute 1984;73(3):667-71.

[11] Dietz WH. Health consequences of obesity in youth: childhood predictors of adult disease. Pediatrics 1998;101(3 Pt 2):518-25.

[12] World Health Organization task force on adolescent reproductive health. World Health Organization multicenter study on menstrual and ovulatory patterns in adolescent girls. I. A multicenter cross-sectional study of menarche. J Adolesc Health Care 1986;7:229-235.
[13] McDowell MA, Brody DJ, Hughes JP. Has age at menarche changed? results from the national health and nutrition examination survey (NHANES) 1999-2004. Journal of Adolescent Health 2007;40(3):227-31.

[14] Dambhare DG, Wagh SV, Dudhe JY. Age at menarche and menstrual cycle pattern among school adolescent girls in central India. Global journal of health science 2012;4(1):105-11.

[15] Nair MK, Chacko DS, Darwin MR, et al. Menstrual disorders and menstrual hygiene practices in higher secondary school girls. The Indian Journal of Pediatrics 2012;79(1):74-8.

[16] Kaplowitz PB, Slora EJ, Wasserman RC, et al. Earlier onset of puberty in girls: relation to increased body mass index and race. Pediatrics 2001;108(2):347-53.

[17] Frisch RE, Revelle R. Height and weight at menarche and a hypothesis of critical body weights and adolescent events. Science 1970;169(3943):397-9.

[18] Teilmann G, Pedersen CB, Jensen TK, et al. Prevalence and incidence of precocious pubertal development in Denmark: an epidemiologic study based on national registries. Pediatrics 2005;116(6):1323-8.

[19] Ashtekar SV, Kulkarni MB, Sadavarte VS, et al. Analysis of birth weights of a rural hospital. Indian Journal of Community Medicine 2010;35(2):252-5.

[20] Terry MB, Ferris JS, Tehranifar P, et al. Birth weight, postnatal growth, and age at menarche. American journal of epidemiology 2009;170(1):72-9.

[21] Al-Awadhi N, Al-Kandari N, Al-Hasan T, et al. Age at menarche and its relationship to body mass index among adolescent girls in Kuwait. BMC Public Health 2013;13:29. 